\title{
O Impacto da Ocupação de Fundo de Vales em Áreas Urbanas - Estudo de caso Lago Igapó Londrina - PR
}

The Impact Of Occupation at Valey Bottom in Urban Areas - Case Study lgapó Lake Londrina - PR

El impacto de la ocupación del Fondo del Valle en zonas urbanas - Estudio de caso Lago Igapó Londrina - PR

\author{
Alexandro Gasparini Larocca \\ Mestrando, UEM, Brasil \\ alexandrogasparini@yahoo.com.br
}

Carolina Cardoso

Mestranda, UEM, Brasil carolinac.arq@hotmail.com

Bruno Luiz Domingos De Angelis

Professor Doutor, UEM, Brasil brucagen@uol.com.br 


\section{RESUMO}

A atividade humana gera impactos ambientais, sendo eles positivos ou negativos. A identificação destes pode ser vista como uma ferramenta que auxilia no planejamento urbano. Assim, a pesquisa teve como objetivo principal analisar os impactos da ocupação do fundo de vale em áreas urbanas. $O$ estudo de caso foi o Lago Igapó 2 na cidade de Londrina - PR, onde utilizou-se como metodologia para Avaliação do Impacto Ambiental, a Matriz de Leopold, também conhecida como matriz de interação, onde é possível avaliar os impactos geo-físicos, biológicos e antrópicos. Como resultado, o estudo demonstrou como está o lago em questão atualmente sendo identificado que um dos principais impactos causados no lago o assoreamento devido a fato de nas proximidades do lago existir diversas obras de construção, desencadeado principalmente a partir da década de 90 , onde o bairro Gleba Palhano começou a ser desenvolvido.

PALAVRAS-CHAVE: Ocupação antrópica, fundo de vale, Lago

\section{SUMMARY}

Human activity generates environmental impacts, whether positive or negative. The identification of these can be seen as a tool that assists in urban planning. Thus, the main objective of the research was to analyze the impacts of valley fund occupation in urban areas. The case study was Lake Igapó 2 in the city of Londrina - PR, where the Leopold Matrix, also known as the interaction matrix, was used as the methodology for Environmental Impact Assessment, where it is possible to evaluate the geo-physical impacts, biological and anthropogenic. As a result, the study demonstrated how the lake in question is currently being identified that one of the major impacts caused in the lake to silting due to the fact that in the vicinity of the lake there are several construction works, triggered mainly from the 90 's, where the Neighborhood Gleba Palhano began to be developed.

KEY WORDS: Antropic Ocupation, Urban Rivers, Lake

\section{RESUMEN}

La actividad humana genera impactos ambientales, que son positivos o negativos. La identificación de estos puede ser visto como una herramienta que ayuda en la planificación urbana. Por lo tanto, la investigación tuvo como objetivo analizar los impactos de ocupación fondo del valle en las zonas urbanas. El estudio de caso fue el lago Igapó 2 en la ciudad de Londrina - PR, donde fue utilizado como una metodología para la evaluación del impacto ambiental, la Matriz de Leopold, también conocida como matriz de interacción, donde es posible evaluar los impactos geofísicos, biológico y antrópico. Como resultado, el estudio demostró que es el lago en cuestión están identificando actualmente que uno de los principales impactos en la sedimentación del lago debido al hecho de que cerca del lago sea varias obras de construcción, debido fundamentalmente a partir de los años 90, donde el Gleba Palhano barrio comenzó a desarrollarse.

PALABRAS CLAVE: Ocupación Antrópica, ríos urbanos, Lagos 


\section{INTRODUÇÃO}

Atualmente a população mundial é de 7.3 bilhões de habitantes (ONU, 2015). Nos últimos doze anos, esta teve um aumento de aproximadamente 1 bilhão de pessoas, onde existem perspectivas de crescimento, porém de forma menos acentuada, nos próximos anos. Dez anos atrás a população crescia em torno de $1.24 \%$ ao ano, hoje esse percentual passou para $1.18 \%$ ao ano, o que em números representa um aumento de 83 milhões de habitantes. Com as projeções, a quantidade de habitantes aumentará mais de 1 bilhão de pessoas nos próximos 15 anos, alcançando assim população de 8.3 bilhões em 2030, chegando a 9.7 bilhões e em 2050 (ONU 2015).

No Brasil, nas últimas décadas, apresentou significativo aumento populacional. Atualmente a população é estimada em 207.848 milhões de habitantes, sendo que com as projeções da ONU a população nacional chegará aos 238.270 milhões em 2030 (ONU, 2015).

No Brasil, ocorreu um processo de urbanização acelerado, principalmente depois dos anos 1960, sendo que entre os anos de 1970 e 2010 o índice de urbanização brasileira foi o maior registrado na América Latina. Atualmente essa taxa é de $86,53 \%$, fazendo do Brasil um país urbano, com mais de 5.500 cidades, vale ressaltar que a maioria destas foi criada nos últimos 30 anos.

Com o crescimento acelerado da taxa de urbanização no Brasil, as cidades estão crescendo de forma desordenada. Apesar de trazer benefícios para as cidades, esse fato acarreta o comprometimento do ambiente urbano, devido à expansão urbana não considerar as características naturais do meio. Assim, surgem então os diversos tipos de impactos ambientais, que são subdivididos em físicos, biológicos, sociais, econômicos e culturais.

Apesar de atingirem o meio urbano como um todo, esses impactos se refletem de forma mais acentuada em áreas de fundo de vale, uma vez que estes locais possuem características ambientais importantes, tendo influência direta principalmente nos recursos hídricos que cortam a cidade e seu entorno.

O objetivo deste artigo é analisar os impactos ambientais, a partir do meio geo-físico, biológico e antrópico, ocorrentes no Lago Igapó 2, localizado na cidade de Londrina - Paraná. Por meio do estudo é possível verificar quais são os impactos que causam maiores problemas a este fundo de vale, que foi represado para transformação em quatro lagos.

O método utilizado na pesquisa é a análise visual desenvolvida por meio da Matriz de Leopold, onde é destacado a causa e o efeito do impacto no objeto de estudo. É discutido sobre a natureza na cidade, onde são apresentadas as legislações federais que incidem sobre a proteção de áreas de proteção permanente. Ainda são pautados os impactos causados às áreas de proteção ambiental em zonas urbanas. Por último é apresentada a tabela onde é mostrado a classificação da causa do impacto e seu efeito sobre o fundo de vale. 


\section{MÉTODO}

Para a análise do objeto de estudo, foi utilizado como o método da matriz de interação ou Matriz de Leopold, escolhido devido a facilidade de visualização dos impactos sobre os diferentes componentes do ambiente, nos quais foram separados em meio geo-físico, biológico e antrópico.

Segundo Ribeiro (1999) as matrizes de interação são amplamente empregadas desde a década de 1970. Estas ferramentas são um dos mais conhecidos métodos para Avaliação de Impacto Ambiental, e que possibilita estabelecer as interações entre os parâmetros ambientais e suas respectivas ações associadas aos processos de transformação, descrevendo a magnitude e intensidade do impacto no meio ambiente. Ribeiro (1999), acrescenta que estas funcionam como listagens bidimensionais, sendo dispostas nos eixos vertical e horizontal as ações para implementar um projeto e os fatores ambientais que podem ser afetados, respectivamente. A interação destes fatores é obtida por meio do cruzamento das linhas com as colunas, chamadas de quadrículas, para as quais é possível atribuir fatores de ponderação.

Para utilizar a Matriz de Leopold, a análise deve ser dividida em duas etapas. De acordo com Ribeiro (1999), a primeira é a identificação das causas e os efeitos ambientais. Nesse estudo de caso essas causas, destacadas nas colunas, são: as avenidas marginais, ruas asfaltadas, loteamentos, assentamentos informais, áreas verdes, eventos itinerantes, retenção de água, mata ciliar natural, mata ciliar modificada e o reflorestamento. Os efeitos são apresentados nas linhas da matriz. Na segunda etapa é realizada a análise dos impactos causados no fundo de vale. Após a análise das possíveis interações, são dispostos os valores para cada ação. Na matriz original são atribuídos valores de 0 a 10 com o sinal de positivo (+) caso o impacto seja considerado benéfico, e da mesma maneira, para os impactos considerados negativos, o símbolo negativo (-) com valores de 0 a 10.

Para a leitura das análises ficarem mais dinâmicas, adaptou-se a escala de valores numéricos pela escala de cores, sendo atribuída para os impactos negativos às cores vermelho, amarelo e laranja (alto impacto, médio impacto e baixo impacto) e para o impacto positivo uma escada de tons de verde: verde claro, verde médio e verde escuro, identificando impactos alto, médio e baixo, respectivamente. Para impactos que não são significativos ou inexistentes utilizou-se à cor cinza claro. É necessário salientar que as notas (cores) atribuídas a esta análise são de acordo com a percepção dos autores.

\section{A NATUREZA NA CIDADE}

A migração da zona rural para a área urbana, no Brasil, teve um crescimento acelerado, principalmente a partir da década de 1960. A urbanização está crescendo cada vez mais rápido e, por outro lado, a qualidade de vida da maior parte da população urbana é cada vez menor, principalmente em países em desenvolvimento (ONU, 2015).

Em decorrência desse crescimento acelerado e da falta de planejamento urbano, começam a aparecer os problemas como alagamentos, as ilhas de calor, chuvas ácidas e a degradação da 
qualidade do ar e dos recursos hídricos do meio urbano. Existem casos que a ocupação irregular de fundo de vales aparece como uma das principais causas para a degradação do meio ambiente.

Araújo (2002), diz que as cidades nascem a partir dos cursos d'água, porque além de abastecerem as cidades com água potável, os rios funcionam como canal de comunicação e de eliminação de resíduos sanitários. Ao longo dos rios, córregos, lagos etc., deveriam ser analisados as normas que regulam as Áreas de Preservação Permanente (APPs).

De acordo com o Ministério do Meio Ambiente (2016), as APPs foram instituídas pelo Código Florestal pela Lei $n=12.651$ de 25 de maio de 2012. Essa lei identifica os espaços territoriais protegidos pela legislação, que podem ser áreas urbanas e rurais, privadas ou públicas e cobertas ou não pela vegetação nativa.

$\mathrm{O}$ art. 2 do Código Florestal estabelece as APPs e descreve as áreas de proteção, que são as florestas e demais formas de vegetação naturais situadas ao longo de rios ou de qualquer curso d'água, desde o nível mais alto em faixa marginal, sendo que a largura da faixa de proteção é determinada pela largura do curso d'água (Quadro 1).

Quadro 1: Faixa de preservação em detrimento da largura do curso d'água.

\begin{tabular}{lc}
\multicolumn{1}{c}{ LARGURA MíNIMA DO CURSO D'ÁGUA } & FAIXA DE PRESERVAÇÃO (MíNIMA) \\
\hline 10 metros & 30 metros \\
\hline 10 a 50 metros & 50 metros \\
\hline 50 a 200 metros & 100 metros \\
\hline 100 a 600 metros & 200 metros \\
\hline acima de 600 metros & 500 metros \\
\hline
\end{tabular}

Fonte: Código Florestal, 2012.

Ainda de acordo com a legislação, as áreas de proteção das APPs podem ser ao redor de lagoas, lagos ou reservatório de água sendo estes naturais ou artificiais, nas nascentes, também chamadas de olho d'água, qualquer que seja a sua situação topográfica.

A faixa de proteção altera conforme o tipo de reservatório, sendo assim o Conselho Nacional do Meio Ambiente (CONAMA) criou a resolução $n^{\circ} 302 / 2002$, que trata dos lagos e reservatórios artificiais e estabelece a largura mínima em projeção horizontal ao redor dos reservatórios artificiais que devem ser medidos a partir do nível máximo normal (Quadro 2).

Quadro 2: Tipos de Reservatórios e faixas de proteção

\begin{tabular}{lc}
\multicolumn{1}{c}{ TIPOS DE RESERVATÓRIOS } & FAIXA DE PRESERVAÇÃO (MíNIMA) \\
\hline Reservatórios artificiais situados em áreas urbanas consolidadas & 30 metros \\
\hline $\begin{array}{l}\text { Reservatórios artificiais situados em áreas rurais } \\
\text { Reservatórios para geração de energia elétrica com até 10 } \\
\text { hectares }\end{array}$ & 15 metros \\
\hline $\begin{array}{l}\text { Reservatórios artificiais não utilizados em abastecimento } \\
\text { público ou geração de energia elétrica com até } 20 \text { hectares em } \\
\text { área rural }\end{array}$ & 15 metros \\
\hline
\end{tabular}

Fonte: CONAMA, 2002.

De acordo com o Ministério do Meio Ambiente (2016) as áreas de preservação ambiental devem proteger o solo para prevenir acidentes relacionados à ocupação irregular de encostas; e os cursos d'água para evitar as enchentes, a poluição e o assoreamento dos rios; além de 
manter a permeabilidade do solo para evitar inundações e auxiliar na recarga de aquíferos. A função ecológica para refúgio da fauna é destacada, principalmente em áreas verdes localizadas no perímetro urbano; bem como auxiliar na diminuição do desequilíbrio climático urbano como o desconforto térmico e ambiental e o efeito de ilha de calor.

De acordo com a Comissão das Comunidades Europeias (1990) o aumento geral do tempo livre dedicado ao lazer fez com o que os cidadãos se tornassem mais conscientes do valor e da importância dos espaços verdes dentro e junto da cidade. Os locais ao redor das cidades tem também grande importância. Em casos como o de Luxemburgo, Bruxelas e Berlim que possuem extensas áreas de floresta junto aos limites urbanos faz com que essas áreas ofereçam habitat para a vida natural e atividades recreativas para a população.

\subsection{IMPACTOS DA OCUPAÇÃO DE FUNDO DE VALE}

Apesar dos benefícios, principalmente na qualidade de vida da população, as APPs em áreas urbanas possuem, em sua maioria, uma certa degradação. Em relação aos impactos causados pela ocupação irregular de fundo de vale, é possível destacar os principais problemas referentes ao saneamento ambiental que atingem as cidades brasileiras: o aumento da demanda por água, a vazão de águas, e da quantidade de resíduos sólidos urbanos, além da vazão do escoamento superficial. Como resultado tem-se uma degradação maior dos recursos e o crescimento progressivo de problemas para a população.

De acordo com Franco (2001), o conceito de impacto ambiental surgiu no final da década de 1960 em debates nos Estados Unidos, liderados pelo Senador Henry Jackson, que estabelecem a "Carta Magna do Movimento Ambientalista". A carta passou, em 1970, ser o NEPA National Environmental Policy Act, que criou o EIS - Environmental Impact Statement (Declaração de Impacto Ambiental), com a função de prevenir possíveis impactos gerados no processo de desenvolvimento. A legislação americana influenciou a criação de legislações para proteção do meio ambiente no mundo todo, inclusive no Brasil. Depois de mais de uma década da criação do NEPA foi criada a Política Nacional do Meio Ambiente, pela Lei $n^{\circ} 6.938$ de $31 / 8 / 81$ e em seu art. $6^{\circ}$, dentro do Sisnama (Sistema Nacional do meio Ambiente), cria o Conama - Conselho Nacional do Meio Ambiente.

$\mathrm{Na}$ resolução 001 do Conama de 23/1/86, define-se impacto ambiental "como qualquer alteração das propriedades físicas, químicas e biológicas do meio ambiente, causados por qualquer forma de matéria ou energia resultante das atividades humanas" (CONAMA, 1986).

O crescimento acelerado dos núcleos urbanos, aliado à falta ou a ineficiência do planejamento urbano é um dos causadores desses impactos. Porém, esses tipos de problemas poderiam ser minimizados ou até anulados, caso os projetos urbanos se atentassem ao processo de drenagem na área urbana, utilizando esses conhecimentos desde as atividades preliminares do planejamento urbano. O modo como o espaço urbano foi ocupado ao longo do tempo, principalmente em áreas de fundo de vale, desrespeita o ciclo hidrológico natural. 


\subsection{O LAGO IGAPÓ EM LONDRINA}

A área urbana do município de Londrina tem $245,01 \mathrm{~km}^{2}$ (LONDRINA, 2017) e está localizada no norte do Estado do Paraná. A cidade foi fundada em 1929 pela Companhia de Terras do Norte do Paraná e foi emancipada em 12 de dezembro de 1934. Teve um desenvolvimento rápido devido à expansão da cafeicultura. Na década de 1970, a cidade passou por um aumento populacional intenso, de forma que o crescimento urbano ficou prejudicado pela falta de planejamento da ocupação urbana. Nas décadas seguintes, a cidade atraiu ainda mais moradores que buscavam melhorias na área profissional, nos negócios e em atividades sociais. O Lago Igapó (Figura 1), identificado como área de estudo, tem a origem de seu nome em Tupi Guarani, que significa transvasamento de rios, está situado na zona sul da cidade de Londrina.

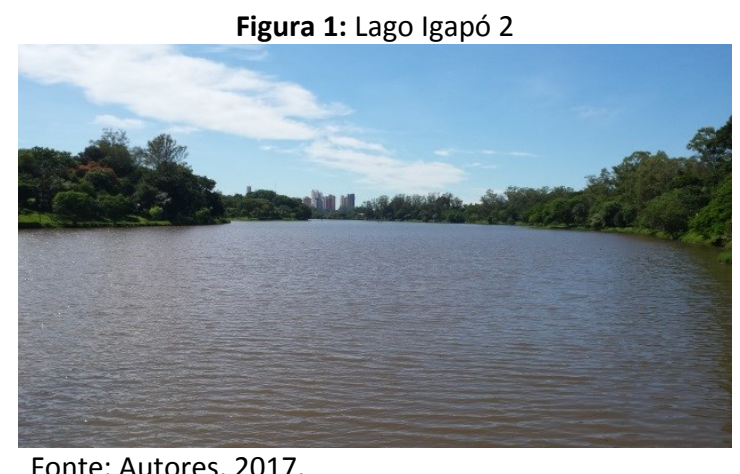

O lago foi criado a partir do represamento do Ribeirão Cambé (Figura 2) e possui 4,5 km de extensão. Nasce a oeste da cidade, na divisa da cidade de Londrina com Cambé, sendo que grande parte do seu leito é em área urbana, seguindo para direção Leste. Foi dividido em Lago Igapó 1,2,3 e 4 pelo fato de ter muitas ruas e avenidas ao longo do curso d'água atravessando o córrego. Para fins desse artigo, a área de recorte será o Lago Igapó 2 , onde é mais utilizado como área de lazer para a população.

Figura 2. Subdivisão do Ribeirão Cambé em Londrina.

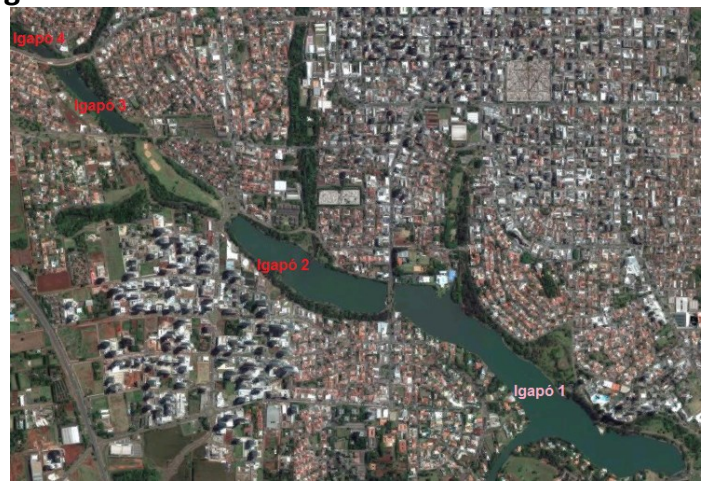

Fonte: Google Earth, 2017. Adaptado pelos Autores. 


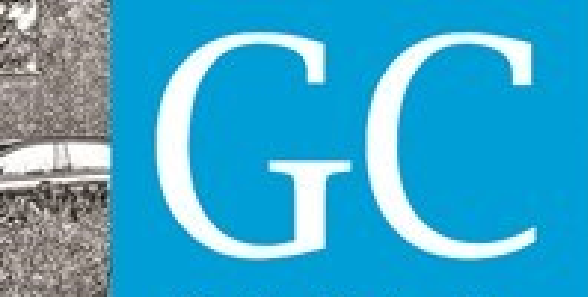

Revista Nacional de

Conforme Bortolo (2010), o Lago foi implantado em 10 de dezembro de 1959, em comemoração ao Jubileu de Prata da cidade. A obra foi idealizada pelo prefeito Antônio Fernandes Sobrinho e seu principal objetivo era melhorar a drenagem deste ribeirão.

No início de sua implantação e logo depois da construção da barragem, o espaço ficou totalmente sem uso e sofreu com um processo de desvalorização. Essa falta de uso como informa Asari e Tuma (1978 apud Bortolo, 2010) se deu devido à presença de curtumes, a circulação de caminhões pesados e a contaminação pela agricultura nas margens do lago., Pelo fato de estar afastado da área que estava ocupada e não ter infraestrutura adequada, o local era pouco utilizado pela população. Após alguns anos da inauguração, foi implantado um depósito de lixo onde atualmente é um conjunto habitacional.

De acordo Bortolo (2010) foi só na gestão do prefeito Dalton Paranaguá (1969-1973) que foi elaborado um projeto para revitalizar o local. Para isso, foi contratado o paisagista Burle Marx, porém seu projeto para o lago não foi totalmente executado. Ainda, construiu-se avenidas nas margens do lago Igapó 1 facilitando o acesso ao local. Com isso, esta área verde começou a ser utilizado pelo público como área de lazer. A revitalização do espaço não era apenas para restaurar a paisagem, mas também tinha como objetivo a restauração da mata atlântica subtropical com espécies nativas.

Durante a década de 1980, houve uma crescente urbanização em direção ao lago, consorciadamente, uma melhora da infraestrutura do espaço, fazendo do lago o espaço público de Londrina mais visitado e melhor visto (BORTOLO, 2010).

Na zona sul de Londrina, as primeiras áreas ocupadas datam de 1943 - Parque Guanabara, projetado antes da construção do lgapó -, 1953 - late Clube e o bairro São Jorge I -, e 1963 Jardim Cláudia. Portanto é possível perceber que anos após a inauguração do lago os loteamentos foram sendo implantados. A margem direita ficou parcialmente desocupada até a década de 1990, quando a iniciativa privada loteou a área com condomínios de alto padrão - o bairro Gleba Palhano -, tornando-se a área mais valorizada da cidade. Com isso, de acordo com Bortolo (2010), esse processo gerou novas formas de revitalização do lago Igapó (Figura 3).

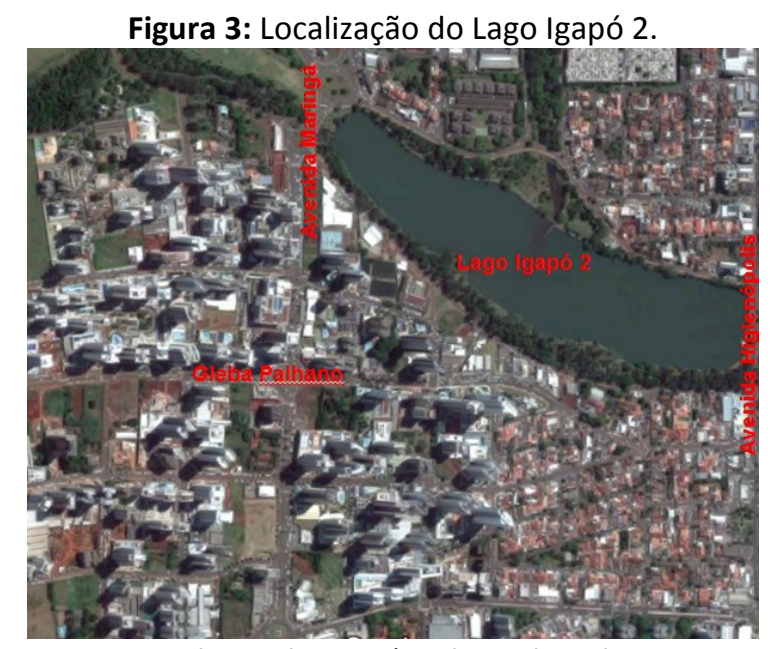

Fonte: Google Earth, 2017). Adaptado pelos Autores. 
Em relação à vegetação, as regras da legislação do CONAMA não são totalmente aplicadas. É possível perceber que as áreas vegetadas mínimas que deveriam ser respeitadas em alguns pontos são inexistentes.

As dimensões do Lago variam entre 10 e 50 metros de largura ao longo de sua extensão. Assim seriam necessárias faixas de 30 a 50 metros de mata ciliar de acordo com cada trecho do lago. No código de obras da cidade de Londrina, só é possível a verticalização a partir dos 30 metros distantes do corpo d'água. No entanto, nota-se em toda a sua extensão construções que desrespeitam estes princípios.

\section{RESULTADOS E CONCLUSÃO}

Neste capítulo serão apresentados os resultados obtidos com a aplicação da Matriz de Leopold, organizados em uma tabela para identificação dos impactos ambientais, sendo eles positivos ou negativos (Tabela 1). Na Linha Causa, foram identificadas as principais causas que podem gerar impactos no fundo de vale. As causas definidas foram as Avenidas Marginais, Ruas Asfaltadas, Loteamento e Edificações, Retenção de Água, Mata Ciliar Natural, Mata Ciliar Modificada e o Reflorestamento.

$\mathrm{Na}$ coluna Efeitos, identificou-se os principais efeitos em relação às causas de impacto ambiental no fundo de vale. Esses foram avaliados em relação a sua magnitude de impacto, sendo alto, médio e baixo para impacto positivo ou impacto negativo.

Tabela 1: Análise do Impacto Ambiental no Lago Igapó 2.

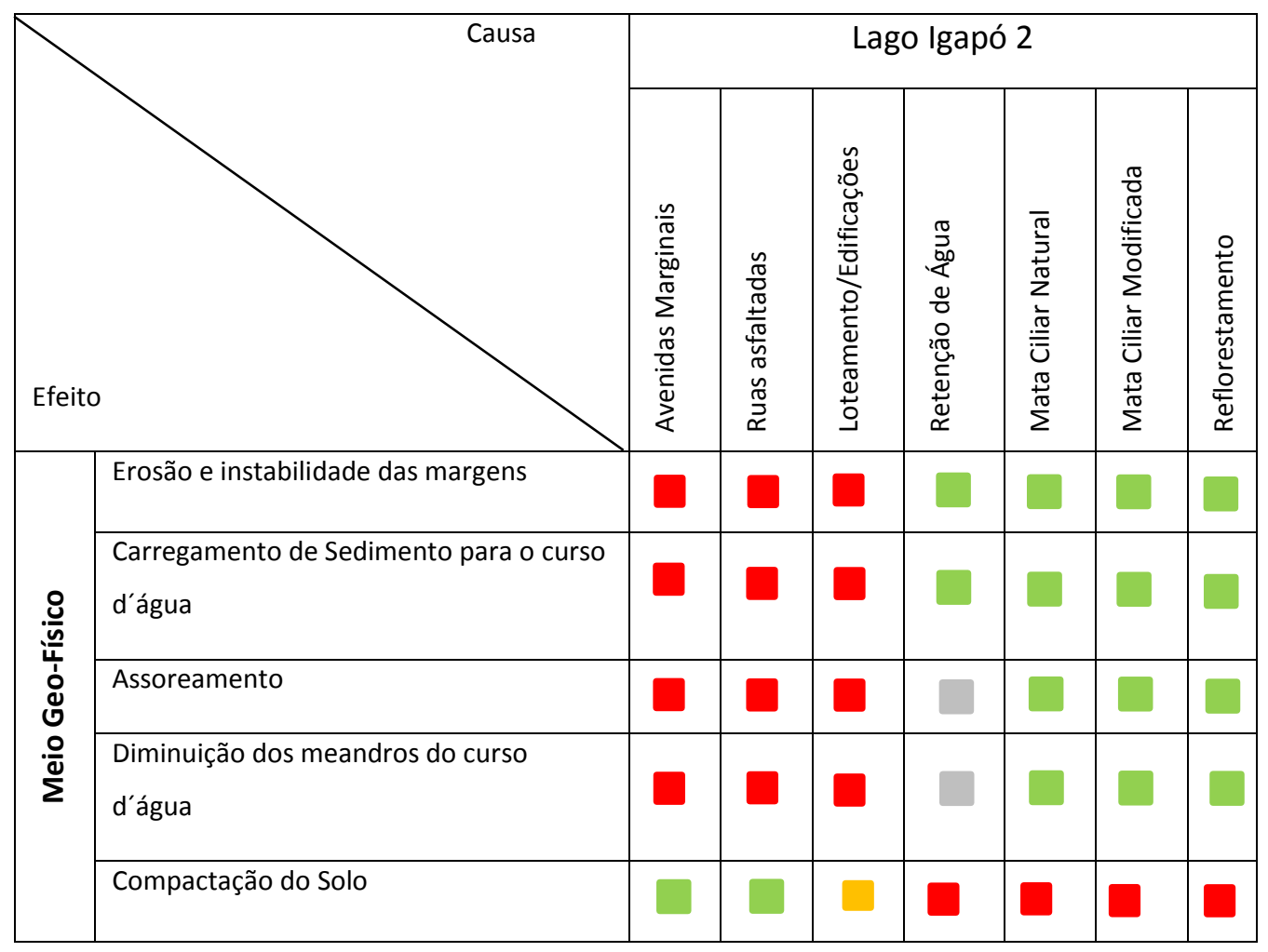




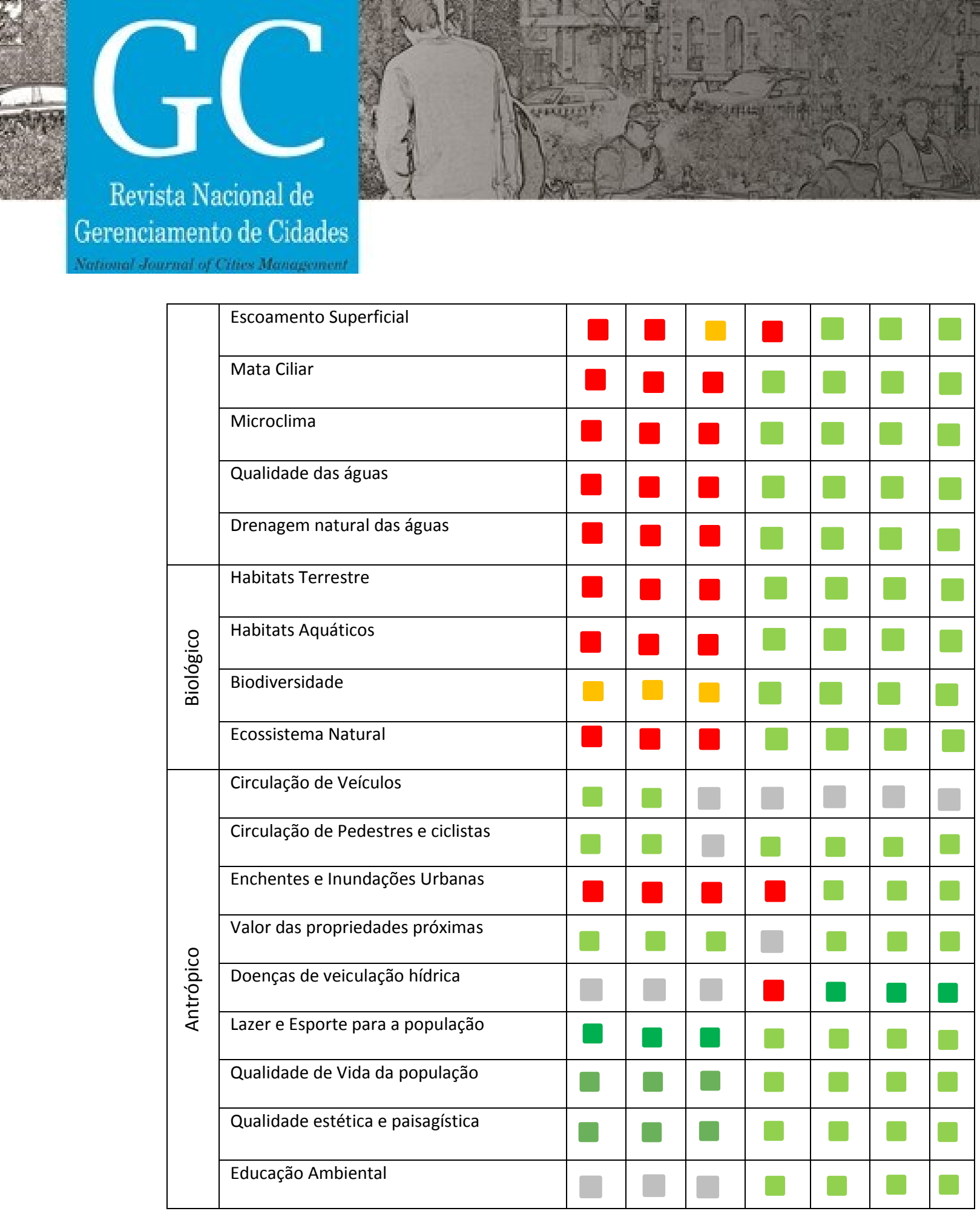

Legenda Magnitude do Impacto

\begin{tabular}{ll}
\hline IMPACTO POSITIVO & IMPACTO NEGATIVO \\
\hline Alto & alto \\
\hline Médio & médio \\
\hline Baixo & baixo \\
\hline sem impacto ou inexistente & \\
\hline
\end{tabular}

Fonte: Leopold et al., (1971) - modificado pelos autores.

Com relação ao meio geo-físico, os impactos negativos foram atribuídos principalmente em relação à impermeabilização do solo das vias e da construção civil nas proximidades do Lago Igapó. Um dos principais impactos negativos acarretados no Lago é o carregamento de 
resíduos para o curso d'água, principalmente pelo bairro Gleba Palhano estar em um processo de consolidação e ainda existir diversos terrenos em construção. Outro fato preocupante, é que estas geralmente não se preocupam em evitar o deslizamento de resíduos, acarretando o assoreamento do lago.

O processo de assoreamento está em estágio avançado (Figura 4), tendo destruído trechos do curso d'água, sendo que a vegetação está avançando para dentro do lago.
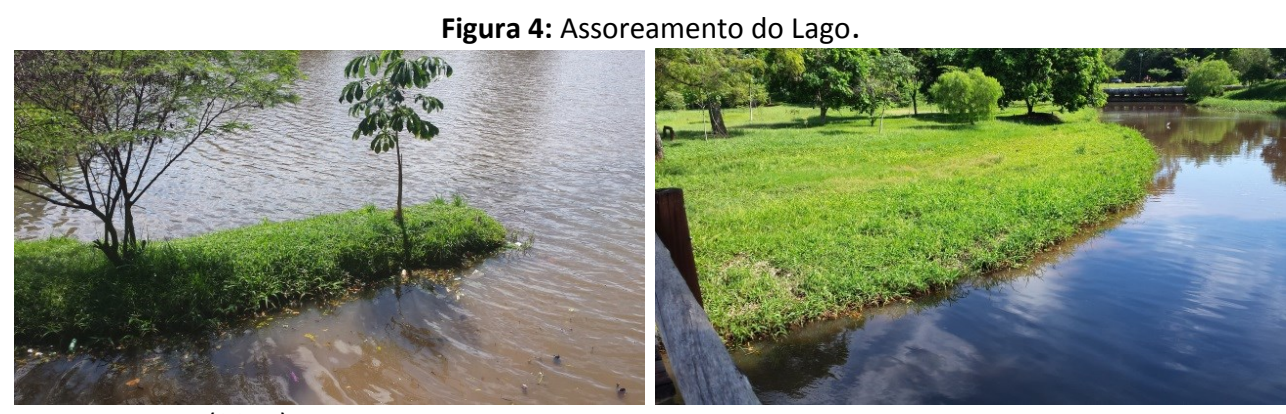

Fonte: Autores (2017).

Situação esta semelhante ao encontrado por Freire et.al. (2013) sobre o assoreamento do Parque Municipal Joaquim Teodoro de Oliveira, em Campo Mourão Pr, onde constatou-se que o principal fator causador deste processo é o carregamento de sedimentos advindos da construção de um novo loteamento, e também de resíduos descartados erroneamente nas residências próximas.

A erosão das margens, ocasionada pela ausência de vegetação, e o escoamento das águas pluviais, que não conseguem ser absorvidas de maneira efetiva pelas galerias urbanas, também contribui para a disposição de sedimentos no lago. Em relação às áreas verdes existentes nas margens do lago, sendo que parte da vegetação é de um projeto paisagístico de Burle Marx, possuem impactos positivos. Isso porque a vegetação possui a capacidade de filtrar e proteger o solo, bem como evita o sedimento de partículas no curso d'água, além de diminuir o escoamento superficial e favorecer a infiltração.

Sobre a análise do meio biológico, a existência de uma massa vegetada auxilia na manutenção da biodiversidade em áreas urbanas, possibilitando maior harmonia no convívio entre o ambiente natural e o ambiente construído. A vegetação existente é responsável pelos maiores benefícios, criando habitat terrestre e auxiliando na manutenção dos habitat aquáticos a partir da criação de sombras, o que favorece a manutenção do microclima adequado. Além disso, por existir a conexão com os outros lagos, funciona como um corredor ecológico, o que facilita a conectividade entre áreas de vegetação, protegendo a biodiversidade (Figura 5). 


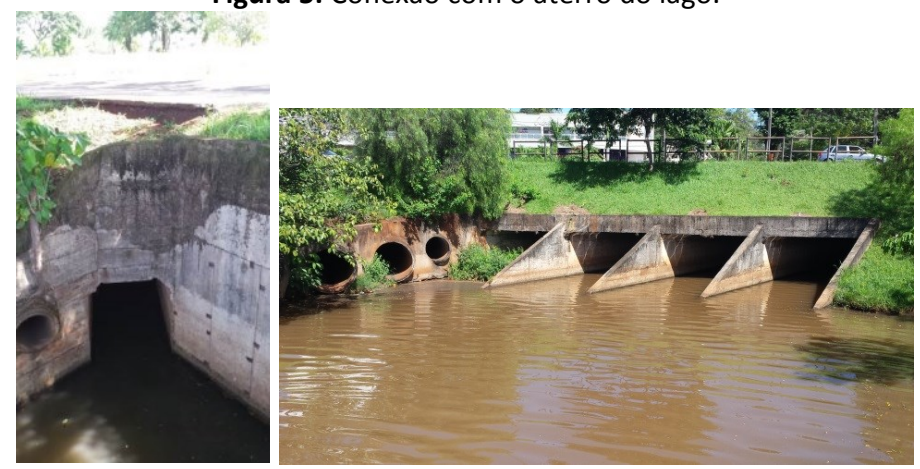

Fonte: Autores (2017)

No meio antrópico, com relação à circulação de veículos, pedestres e ciclistas, mostram impactos positivos, principalmente no que tange às avenidas e ruas próximas asfaltadas, sendo de fácil acesso a população. As áreas verdes também têm impacto positivo na circulação de pedestres e ciclistas, o local possui ciclovia e pista de caminhada, no qual a população utiliza ativamente o local, principalmente no final da tarde para a prática de atividade física.

Quanto ao fator de enchentes e inundações urbanas e suas consequências para o meio antrópico, devido ao fato do lago estar com o problema relacionado ao assoreamento, em períodos de chuvas mais intensas ocorre o transbordamento do lago. Esse fato já foi noticiado no ano de 2012, as áreas assoreadas, onde acarretou na diminuição do meandro do curso d'água, tendo a pista de caminhada encoberta pela água. Com os transbordamentos, a proliferação de doenças de veiculação hídrica tende a aumentar consideravelmente, principalmente se o curso d'água estiver poluído.

Em relação ao valor das propriedades próximas a lago, por ser atualmente considerado uma área nobre, com vias asfaltadas e com massa de vegetação e qualidade paisagística, essas propriedades são muito valorizadas. Com isso é possível melhorar a qualidade de vida da população, influenciando diretamente no lazer e esporte, na qualidade estética e paisagística e na educação ambiental, fazendo com que a população valorize o local.

\section{CONCLUSÃO}

A vegetação natural deveria ser mantida intacta, mesmo em áreas urbanas, o que seria a solução ideal para muitos impactos ambientais negativos acarretados ao fundo de vale.

Diante do artigo, ao analisar o impacto ambiental da ocupação do Ribeirão Cambé, represado para dar lugar ao Lago Igapó, e analisando a situação atual do lago pode-se concluir que é necessário investir em meios de conscientizar a população sobre os problemas causados ao Lago, principalmente ao descartar detritos próximos ao local. No caso das obras de construção civil, seria interessante proteger o solo exposto para evitar o escorregamento de terra e/ou material de construção para o lago.

Uma das necessidades urgentes do lago é o seu desassoreamento. São necessárias medidas mitigatórias, não só no lago em questão, mas em toda a extensão do Ribeirão Cambé (onde estão os 4 lagos) e também em seus afluentes, reduzindo a quantidade de detritos depositados no leito do lago. 
Há ainda a necessidade de estabilizar a erosão que existe na área, sendo que um dos recursos seria a recomposição da mata ciliar de todo o lago e de seus afluentes. Por fim, a necessidade de fiscalização constante nos terrenos próximos com obras ou terrenos vazios sem muretas de proteção e a drenagem do lago.

\section{REFERÊNCIAS}

BORTOLO, Amorim. O Lago Igapó em Londrina - PR. Uma leitura das diferentes formas de produção do espaço urbano. Dissertação (Mestrado) - Universidade Estadual de Londrina (UEL), 2010.

CONAMA - Conselho Nacional do Meio Ambiente. Resolução 001/1986. Disponível em: <http://www.mma.gov.br/port/conama/res/res86/res0186.html >. Acesso em: 10/01/2017.

. Resolução 303/2002. Disponível em:

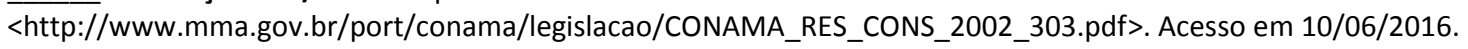

FARR, Douglas. Urbanismo sustentável - Desenho urbano coma Natureza. Tradução Alexandre Salvaterra. Bookman: Porto Alegre, 2013.

FRANCO, Maria de Assunção Ribeiro. Planejamento Ambiental para cidade Sustentável. Annablume: FAPESP. São Paulo, 2001.

FREIRE, V. H. N. ; MIRANDA, Y. C. ; GONZATTO JUNIOR, O. A. ; MEZZOMO, M. M. . Análise Geomorfológica Preliminar do Processo de Assoreamento no Parque do Lago em Campo Mourão. PR. Revista Pantaneira, v. 15, p. 20-30, 2013.

LEOPOLD, L Luna Bergere et al. A procedure for evaluating environmental impact. Geological Survey Circular 645, Washington, 1971.

LONDRINA. Dados demográficos. Disponível em:

$<$ http://www.londrina.pr.gov.br/index.php?option=com_content\&view=article\&id=40:dadosgeograficos\&catid=5:a-cidade\&Itemid=58>. Acesso em 23/03/2017.

MACIEL, Marcela A. As áreas de preservação permanente em área urbana. 0 aparente conflito entre o Código Floresta e a Lei de Parcelamento do Uso do Solo. Disponível em:

<http://www.ambitojuridico.com.br/site/index.php?n_link=revista_artigos_leitura\&artigo_id=8703>. Acesso em: $10 / 06 / 2016$.

MINISTÉRIO DO MEIO AMBIENTE. Disponível em: <http://www.mma.gov.br/cidades-sustentaveis/areas-verdesurbanas/\%C3\%A1reas-de-prote\%C3\%A7\%C3\%A3o-permanente>. Acesso em 15/06/2016.

ONU - Organização das Nações Unidas. World Population Prospects - The 2015 Revisions. Disponível em: <https://esa.un.org/unpd/wpp/Publications/Files/Key_Findings_WPP_2015.pdf>. Acesso em: 18/06/2016.

RIBEIRO, Eloisa Ramos. NASCIMENTO, Bernardo Arantes. FERNANDES, Ana Cristina A. Variaveis ambientais incidentes no processo de avaliação do impacto urbano: proposta metodológica para aplicação de matrizes. VIII Enanpur, 1999.

SANTOS, Rozely Ferreira. Planejamento Ambiental - Teoria e Prática. Oficina dos textos: São Paulo, 2004. 